\title{
The comparation of cultural dimention between Sulawesi, Indonesia and Philippine: a measurement of five Indonesian islands
}

\author{
R Setyaningrum $^{1,2^{*}}$, A R Wijaya ${ }^{1}$ and Subagyo ${ }^{1}$ \\ ${ }^{1}$ Department of Mechanical and Industrial Engineering, Gadjah Mada University, \\ Yogyakarta, Indonesia \\ ${ }^{2}$ Department of Industrial Management, Dian Nuswantoro University, Indonesia. \\ *ratihha@gmail.com
}

\begin{abstract}
The Indonesian archipelago is bordered by many countries, such as Sulawesi island bordered by the Philippines. The culture of Sulawesi allegedly had the same style with the culture of the Filipinos. Several studies have examined the details of Indonesian culture, especially the culture of Sulawesi and the Philippines, but has not studied the details of the cultural dimension measurement of both countries. This study aims to measure the dimensions of Hofstede cultural communities in the Indonesian archipelago and do a comparative study of cultural dimensions of Hofstede to Sulawesi and the Philippines. The data (631 respondents) was analysed using calculations score of Hofstede cultural dimensions consists of the Power Distance Index (PDI), Individualism (IDV), Masculinity (MAS), Long-term orientation (LTO) and Uncertainty Avoidance (UAI). The measurement results of Hofstede cultural dimensions Indonesia is slightly different from the predecessor research. There are several dimensions of Hofstede Indonesian culture which decreased compared to the results of research on the IBM Company, which consists of PDI, UAI, and LTO as well as an increase at IDV and MAS. The geographical position of the region of Sulawesi and the Philippines affect both cultural interactions. Several cultural dimension scores of Sulawesi and the Philippines were relatively close. It shows that Sulawesi and the Philippines have similar cultural dimensions PDI, IDV and MAS. This cultural dimension measurement results expected to contribute to the fields of science related to the cultural mapping of Indonesia and the Philippines.
\end{abstract}

Keywords: Cultural dimension, Indonesia, Sulawesi, Philippines

\section{Introduction}

\subsection{The Geographical and Cultural Overview}

The geographical location of a country will give effect to the culture of other countries that are around. Indonesian region which is next to the Philippines is Sulawesi. The Philippines is an archipelago in the Pacific Ocean, bounded by the Pacific Ocean in the east, south of the Sulawesi Sea, South China Sea in the west and the Luzon Strait in the north. The geographical location of each other would affect the culture of the people in Sulawesi and the Philippines. There is an interaction of culture on both territories (1). Axelrod through his research, previous computational modeling work, has shown cultural diffusion to act quickly to produce zones of homogenous cultures that have difficulty interacting with each other. The study was developed by Reilly who studied how geographic barriers can affect culture flows, rather than how aids to interaction (such as the internet) can affect cultural 
interaction. The results of the study by Axelrod in (1) showed that the geographical conditions of a region will affect the cultural interaction in the region. Some researches have discussed in details of Indonesian cultures especially Sulawesi and The Philipines. The research about the cultures in Sulawesi area were carried out by (2-4). The Philiphine's cultures were studied by (5). Based on the above researches, there is no study about measuring the cultural dimension of Sulawesi's and The Philippines' society.

\subsection{Overview of cultural dimension research}

Some researchers and their works like (6-8) have their own definitions used in different research fields, such as sociology, anthropology and the humanities (9). These elements are common to various definitions, for example (10) treats culture as "the collective programming of the mind that distinguishes the members of one group or category of people from another"' and explains that the 'mind' stands for thinking, feeling and acting.

Hofstede dimensions of research applied to the field of communication and information of an organization. Among others are (11-13). Ergeneli's research (11) showed that the evaluation of responses indicates that a significant \& negative relationship exist between the uncertainty avoidance culture value dimension and overall transformational leadership. Loenard (13) has done a research aimed to build our understanding of cooperation in different societies and contexts, and suggested that there may be a universal view of cooperation across cultures. Chattaraman (12) conducted a study that discusses the context of consumer acculturation, consumption-based social identity, biculturalism, and cultural frame shifting.

Various studies in the field of product development based on national culture Hofstede (14-18) and the incorporation of Hofstede and perceive aesthetics (19-23). Global designing web using Hofstede approach (14). Regional culture originated designer (16), emotional and aesthetic property of the designer to give effect to the product that he designed (15). Coelho (17) vote of personalities who influenced the cultural aspects of the product. On the other hand, Peranginangin (18) has used kansei to design open spaces and the resulting differences in the need for men and women. Fisher \& Fawcett (24) tested the correlation technology, information, design and power to minority communities or immigrant. Fereidouni (25) analyzed the influence of Hofstede dimensions towards advertising in Malayan women (Malaysia, India, and China). Astuti \& Satriani (26) analyzed the color composition of Dayak ethnic as forming the cultural image of refined interior design. Merritt (27) conducted a preliminary study to define the culture of the country to train Customer Relationship Management (CRM), behavioral data taken from 9,000 men pilots in 18 countries to complete the mapping process using Hofstede dimensions.

\subsection{Purpose of the study}

This study aims to measure the dimensions of Hofstede cultural communities in the Indonesian archipelago and do a comparative study of Hofstede cultural dimensions between Sulawesi and the Philippines. The results of the cultural dimension measurement are expected to contribute to the fields of science related to Indonesian and the Philippines culural mapping.

\section{Research Methodology}

\subsection{Participans}

Respondents in the study included Indonesian citizens who live on the island of Sumatra, Java, Kalimantan, Sulawesi, East Nusa Tenggara, Bali and Ambon. The number of questionnaires distributed were 725 questionnaires with a questionnaire return rate of $87 \%$ has been filled properly. Then, the total number of respondents was 631 people filling up Hofstede questionnaire. Job respondents consisted of civil servants (PNS) in the field of education/ universities and employees of private companies/entrepreneurs. Education respondents are very varied covering High School/ Vocational (SMA/SMK), Diploma (D3), Bachelor Degree (S1), Postgraduate (S2 and S3). Demographic factors of respondents are gender, age, and the length-duration of the person staying in 
the area/ region of Indonesia. The respondents' demographic factors on Indonesian islands (Sumatra, Java, Sulawesi, Kalimantan, East Nusa Tenggara, Bali, and Ambon). The sex of the respondents from Sulawesi consisted of women (53.49\%) and men (46.51\%). The age of the respondents from Sulawesi consisted of under 20 years (0\%), aged 21-39 years (89.92\%), aged 40-59 years (9.3\%) and aged 60 years and older $(0.78 \%)$. Year of living in Sulawesi region consisted of a stay of less than 5 years (7.75\%), staying for a range of 6-25 years (44.96\%), lived for 26-50 years (46.51\%) and stayed for 51 years $(0.78 \%)$. The gender of all Indonesian respondents consisted of women $(43.26 \%)$ and men (56.74\%). Age of the respondents as a whole consisted of aged under 20 years (0.63\%), aged 21-39 years (77.02\%), aged $40-59$ years (20:44\%) and aged 60 years and older (0.79\%). Year of living in the territory of Indonesia consisted of a staying for less than 5 years (14.74), staying for a range of 6-25 years (46.28\%), lived for 26-50 years (38.35\%) and stayed for 51 years $(1.74 \%)$.

\subsection{Measure}

This study uses a scale and item questionnaire questions Hofstede's Value Survey Module (VSM) 2013 version (28). Power Distance Index (PDI): Hofstede (10) stated that Power Distance indicates the extent to which a society accepts inequality in power among institutions, organizations and people. Uncertainty Avoidance (UAI): Hofstede (10) also stated that Uncertainty Avoidance is the extent to which members of a society feel uncomfortable with unstructured situations and ambiguity. Individualism (IDV): Individualism in this context is the integration of individuals into primary groups and also the degree to which individuals are supposed to look after themselves or remain integrated in groups. Masculinity (MAS): The masculinity is the extent to which the dominant values (such as assertiveness, the acquisition of money and objects, heroism, achievement, the quality of life, cooperation, relationships and group decisions) in a society are "masculine”. Long-term Orientation (LTO): Hofstede (10) has defined the long-term orientation as "the fostering of virtues oriented towards future rewards, in in particular, perseverance and thrift' 'The key differences between the short-term and long-term orientation dimensions are that in short-term orientation there is respect for tradition, leisure time, personal steadiness and stability; people expect quick results; immediate gratification of needs is expected; spending versus saving and investing has priority.

\subsection{Procedure}

Stratified Random Sampling: the population was divided into certain parts and then the members of each section is taken the sample. This sampling technique is used to map the cultural dimensions of Hofstede. Method of filling the questionnaire was done by asking respondents to fill the questionnaire directly. The number of respondents of this study were 631 people. Questionnaire consisted of 31 questions consisted of 5 questions about the data of respondents and 26 questions about the cultural dimensions of Hofstede. Questions about the respondent data included names/ initials, age, sex, education and jobs. Questions about the cultural dimensions of Hofstede included five dimensions of PDI, IDV, MAS, LTO and UAI, which were randomly distributed by VSM 2013. Each dimension was represented by four questions contained in the Hofstede questionnaire.

\subsection{Data Processing}

The data were processed using statistical analysis and calculation Hofstede cultural dimensions scores. Statistical analysis using SPSS while the calculation of scores of cultural dimensions refer to the VSM 2013 (29).

Index calculation based on the cultural dimension VSM 2013 were presented in equation (1), equation (2), equation (3), equation (4) and equation (5).

$$
\begin{aligned}
& \text { PDI }=35(\mathrm{~m} 07-\mathrm{m} 02)+25(\mathrm{~m} 20-\mathrm{m} 23)+\mathrm{C}(\mathrm{pd} \\
& \mathrm{IDV}=35(\mathrm{~m} 04-\mathrm{m} 01)+35(\mathrm{~m} 09-\mathrm{m} 06)+\mathrm{C}(\mathrm{ic}) \\
& \text { MAS }=35(\mathrm{~m} 05-\mathrm{m} 03)+35(\mathrm{~m} 08-\mathrm{m} 10)+\mathrm{C}(\mathrm{mf}) \\
& \text { LTO }=40(\mathrm{~m} 13-\mathrm{m} 14)+25(\mathrm{~m} 19-\mathrm{m} 22)+\mathrm{C}(\mathrm{ls}) \\
& \text { UAI }=40(\mathrm{~m} 18-\mathrm{m} 15)+25(\mathrm{~m} 21-\mathrm{m} 24)+\mathrm{C}(\mathrm{ua})
\end{aligned}
$$


$\mathrm{mn} \quad$ : question number - $\mathrm{n}$ from Hofstede questionnaire, example: $\mathrm{m} 07$ is question number 7.

C (pd) : : constant value in Power distance index

Based on the above equation, C (pd), C (ic), C (mf), C (ls) and C (ua) is a constant (positive or negative) that depends on the nature of the samples. For example, in equation (1) for the PDI (Power Distance Index). This index normally has a range of about 100 points between very small power distance and very large power distance countries. $\mathrm{C}(\mathrm{pd})$ is a constant (positive or negative) that depends on the nature of the samples and it does not affect the comparison between countries. It can be chosen by the user to shift her/his PDI scores to values between 0 and 100 .

Some previous studies showed various ways of determining the value of C (pd), C (ic), C (mf), C (is) and $C$ (ua) in different ways. Research by $(30,31)$ defined a constant value in the same way, the value of C (ic) and C (ua) $=+50$, while the value of C (pd), C (mf) and C ( ls) $=0$. The calculation is capable of producing scores of cultural dimensions in the range of 0 and 100. Based on the predecessor research, determination of the constant value for the scores of Indonesian cultural dimensions value $\mathrm{C}$ $(\mathrm{pd})=0$; the value of $\mathrm{C}$ (ic) and $\mathrm{C}(\mathrm{ua})=+50$, while the value of $\mathrm{C}(\mathrm{mf})$ and $C$ (ls) $=+75$. By using a constant value, the scores of Indonesian cultural dimensions in the range of 0 and 100 can be obtained.

\subsection{Data Analysis}

The study involved 631 respondents who are the original citizens of Indonesia, which spread all over Indonesia. Respondents consisted of women (43.26\%) and men (56.72\%). The age of respondents in this study were between the age range of 21-59 years (97.46\%) consisting of age 21-39 years (77.02\%) and $40-59$ years (20:44\%). The survey respondents' years of living in Indonesia were in the range of 6-50 years (84.63\%), which consisted of staying for 6-25 years (46.28\%) and staying for 26-50 years (38.35\%). Based on the description of the respondents' demographic condition, it can be concluded that the respondents of this research was the respondents in productive age and already represented the character of Indonesian culture that is can be seen from their length of stay in the Indonesian territory. Reliability test results on the five dimensions of Hofstede culture was indicated by Cronbach Alpha values. The dimensional reliability test of PDI has a value of Cronbach's alpha of 0.654, IDV dimension has a Cronbac's alpha value of 0.783, the dimensions of MAS has a Cronbach's alpha value of 0.797, the dimensions of LTO has a Cronbach's alpha value of 0.711 and had UAI dimensions Cronbach's alpha value of 0.6. Based on the results of reliability test with the average value of Cronbach's alpha of 0.709 for all five dimensions, it can be concluded that the statement of the Hofstede questionnaire is reliable. Based on VSM in 2013 stated that the rule of thumb for a test of reliability is a value over 0.700 .The new items in the new version were chosen because of the review on their similarity to other items in reliable studies, but the reliability of the new dimension scores can not be proven a priory.

\section{Research Result}

3.1. The Calculation Results of Hofstede Cultural Dimension in Indonesian Archipelago.

This study assesses the cultural dimension to every island in Indonesia covering Sumatra, Java, Sulawesi, Kalimantan, NTT, Bali and Ambon). The calculation results of Hofstede cultural dimensions of each island are presented in Table 3 while the results of the calculation of Hofstede cultural dimensions throughout Indonesia are presented in Table 4.

Calculation of the cultural dimension of PDI, IDV, MAS, LTO and UAI for the islands of Sumatra, Java, Sulawesi, Kalimantan, (NTT, Bali and Ambon) are presented in Table 3. The Hofstede cultural dimensions calculation results of the Indonesian archipelago are presented in Figure 1.

Tabel 1. The Calculation Hofstede Cultural Dimensions in the Indonesian archipelago.

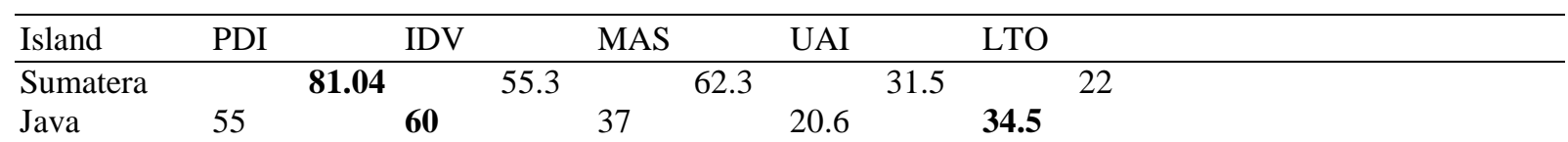




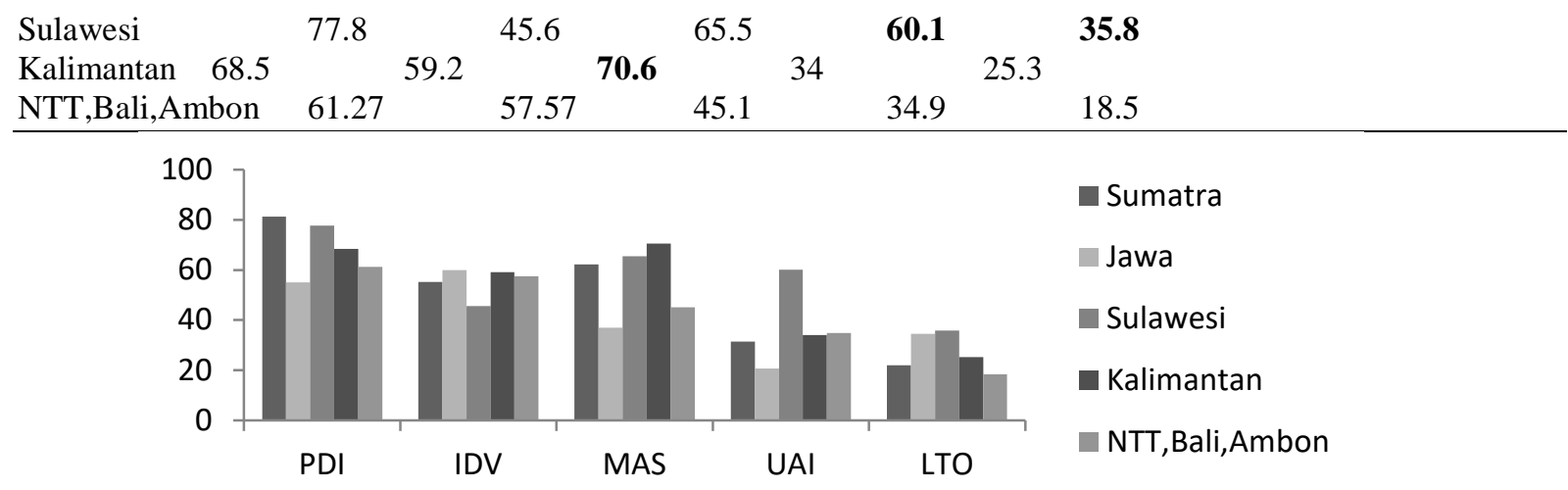

Figure 1. The Hofstede cultural dimensions scores of the Indonesian archipelago.

Based on Table 3 and Figure 1, it shows that the highest PDI score is in Sumatra (81.04), the highest IDV score is in Java and Kalimantan (60 and 59.2), the highest MAS score is in Kalimantan (70.6), the highest UAI score is in Sulawesi (60.1) and the highest LTO score is in Sulawesi (35.8).

\subsection{The Comparison of Cultural Dimensions between Sulawesi, Indonesia and the Philippines}

The Hofstede cultural dimensions calculation results of Sulawesi, Indonesia, Indonesia non-Sulawesi and the Philippines are presented in Table 4. The display graphics of Hofstede cultural dimensions calculation results in Sulawesi, Indonesia, Indonesia non-Sulawesi and the Philippines are presented in Figure 2.

Tabel 4. The Calculation of Hofstede Cultural Dimensions in Sulawesi, Indonesia and the Philippines.

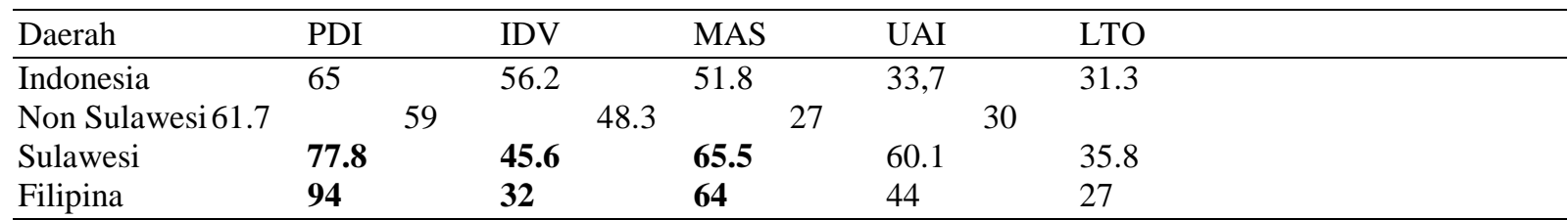

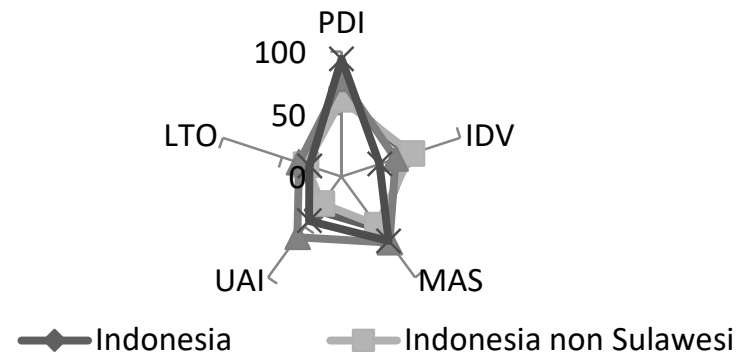

Figure 2. Hofstede cultural dimensions of Sulawesi, Indonesia and the Philippines.

Based on Table 4 and Figure 2 showed that the highest PDI score is the Philippines. The highest IDV score is Indonesia non-Sulawesi. The highest MAS, UAI and LTO score is Sulawesi.

\subsection{The Comparasion of Cultural Dimensions in Indonesia with the Previous Research Results} The measurement results Hofstede's cultural dimensions of Indonesia in Table 4 shows the differences in the Hofstede research results (32) on IBM Company. The differences in Hofstede cultural dimensions score in Indonesia is presented in Figure 3. 


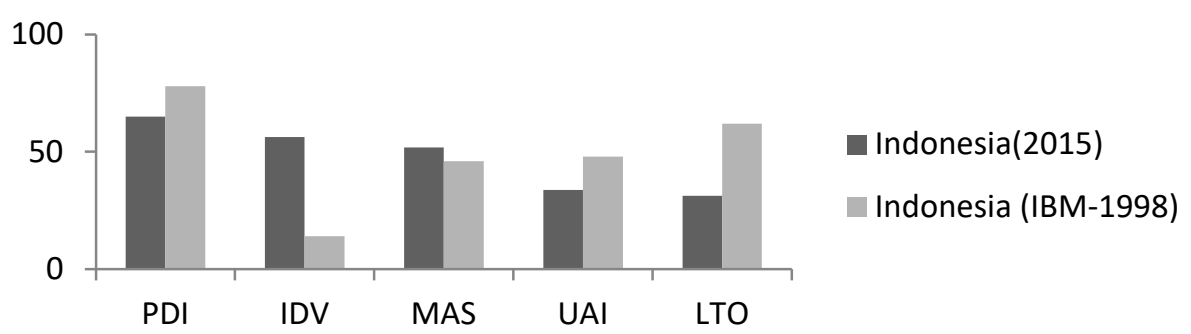

Figure 3. Comparison of the Indonesian cultural dimensions results score.

Based on Figure 4, it is indicated that the Indonesian cultural dimensions decreased compared to the results of research on IBM. The PDI (16.7\%), UAI (29.7\%), and LTO (49.5\%). In addition, there is a cultural dimension in Indonesia, which increased in IDV (300\%) and MAS (12\%).

\section{Discussion}

4.1. The comparison of Cultural Dimension of The Indonesian Archipelago with The Previous Research Results

This research complements the research done by (10) on the IBM employee. He presented dimension scores of Indonesian culture. They were PDI (78), IDV (14), MAS (46), UAI (48) and LTO (62). Indonesia is an archipelago with demographic conditions separated by oceans. In order to assess the cultural dimension of Indonesia, it should be done in more detail to accommodate the location of the Indonesian islands separated by oceans.

The comparison of Hofstede on cultural dimensions of Indonesia is presented in Figure 2, which shows that some Hofstede Indonesian cultural dimensions has decreased compared to the research results on IBM, which consisted of PDI (16.7\%), UAI (29.7\%), and LTO (49.5\%). The Indonesian cultural dimension character like the cultural dimension of developed countries character development shows that PDI has decreased, IDV increased and UAI decreased.

The differences in Hofstede's cultural dimensions of Indonesia over two decades shows that the cultural dimension has changed with the passage of time. Taras (8) conducted a meta-analysis to show culture is above to become even more dynamic and exicting than it ready. Further, (33) examined empirically wheter national culture has an impact on e-government development in 84 countries around the world. It is widely acknowledged that culture has a significant influence on customer behavior and technology diffusion $(34,35)$. The study shows that the cultural dimensions of dynamic change and cultural influence behavior and diffusion of technology in developing countries.

On the other hand, there is a cultural dimension in Indonesia which increased in IDV (300\%) and MAS (12\%). IDV cultural dimension in Indonesia rose to 56.2, the IDV score almost equivalent to a score of IDV in some developing countries such as Switzerland (68), United States (91), and Australia (90). It shows that the Indonesian people have a tendency to increase the degree of individualism against social groups such as the community of developing countries. There are cultural differences between Asia and Europe based on the research results by (36) citing the research by $(37,38)$. Moreover, the differences in intergovernmental cooperation in ASEM make the differences between Asian and European culture visible(37,38). Asians focus more on furthering the aims of collectives, while Europeans focus more on the aims of individuals $(39,40)$. MAS is associated with differences in gender roles and individual preferences, scores of cultural dimensions of MAS in Indonesia has increased $12 \%$. MAS is also associated with a preference of individuals in society. Masculinity stands for a society in which social gender roles are distinct. Clearly, men are supposed to be assertive, tough and focused on material success; women are supposed to be more modest, tender and concerned with the quality of life. Femininity: both men and women are supposed to be modest, tender and concerned with quality of life (32). Countries with high MAS emphasize on achieving values of heroic and firm. 
Conversely, countries with low MAS emphasize the individual to maintain a relationship by regarding to others.

\subsection{Comparison of the cultural dimension of Sulawesi, Indonesia and the Philippines}

According to the geographical position, the island of Sulawesi lies adjacent to the Philippines. The geographical conditions will affect the culture of the people living in Sulawesi and the Philippines. This opinion was supported by the research as evidenced by measurements of Hofstede cultural dimensions of Sulawesi and the Philippines. Based on the graph in Figure 2, it shows that compared with the islands of Sumatra, Java, Kalimantan, East Nusa Tenggara, Bali and Sulawesi, Ambon score is closer to the cultural dimension scores of the Philippines. Sulawesi cultural dimension score included PDI (77.8), IDV (45.6), MAS (65.5) and UAI (60.1), approaching the score of the Philippine cultural dimensions. It shows that Sulawesi and the Philippines have similar cultural dimensions on PDI, IDV and MAS. PDI is defined as how much distance power in society, in which Sulawesi and the Philippines have a high PDI scores. MAS dimension to Sulawesi and the Philippines are included in the category of high MAS. Country with high MAS values (e.g the United States) distinguish clearly that men should be more aggressive than women. Men should focus on material success and women should be simpler and pay attention to the quality of life. However, countries with a low MAS value view that men and women should apply a simple and attention to the quality of life. These results are consistent with the research carried out by (1) showed that the geographical conditions of a region will affect the cultural interaction in the region.

\section{Conclusion}

This study complements the predecessor research related to the culture of Indonesia. The assessment of cultural dimension to the islands in Indonesia produced the highest score for each dimension including; the highest PDI score is in Sumatra, the highest IDV score is in Java, the highest MAS score is in Kalimantan, the highest UAI and LTO score are in Sulawesi. The Hofstede's measurement results on cultural dimensions in Indonesia are slightly different from the predecessor research conducted by the IBM Company. The geographical position of the region of Sulawesi and the Philippines affect both cultural interactions. There are several scores of cultural dimensions of Sulawesi and the Philippines, which have relatively close. It shows that the Sulawesi and the Philippines have similar cultural dimensions of PDI, IDV and MAS. The results of this study related to the cultural dimension of Sulawesi, Indonesia and the Philippines could be used to develop research by applying Hofstede's cultural dimensions in the field of sociology, anthropology, humanity, communication and information organization, as well as the development of culture-based products.

\section{References}

1. Rilley JL. Modeling Geographic Effects on Cultural Change: How Physical Barriers Structure Social Networks and Change the Rate of Cultural Diffusion. University of California; 2005.

2. $\quad \mathrm{Li}$ TM. Relational Histories and the Production of Difference on Sulawesi's Upland Frontier. J Asian Stud. 2001 Feb;60(1):41.

3. Acciaioli G. From Economic Actor to Moral Agent: Knowledge, Fate and Hierarchy among the Bugis of Sulawesi. Indonesia. 2004;78:147-80.

4. Bodden M. Regional Identity and National Theatre in South Sulawesi. J Southeast Asian Stud. 2004 Feb 1;44(1):24.

5. Villanueva ZV. Cultural Encounters and Transformation of Early Historical Polities on Lubang Island, The Philippines CA.A.D. 1200-1800. The University of Arizona; 2009.

6. $\quad$ Chanchani S, Theivananthampillai P. Typologies of Culture. SSRN Electron J. 2009 Jul 30;

7. $\quad$ Hall S. Cultural studies: two paradigms. Media, Cult Soc. 1980 Jan 30;2(1):57-72.

8. Taras V, Steel P, Kirkman BL. Improving national cultural indices using a longitudinal metaanalysis of Hofstede's dimensions. J World Bus. 2012 Jul 1;47(3):329-41.

9. Kaasa A. Culture, religion and social capital: evidence from European regions. Int J Sociol Soc 
Policy. 2015 Oct 12;35(11/12):772-94.

10. Hofstede GH. Culture's consequences: comparing values, behaviors, institutions, and organizations across nations. Thousand Oaks: Sage Publications; 2001. 596 p.

11. Ergeneli A, Gohar R, Temirbekova Z. Transformational leadership: Its relationship to culture value dimensions. Int J Intercult Relations. 2007 Nov 1;31(6):703-24.

12. Chattaraman V, Rudd NA, Lennon SJ. Identity salience and shifts in product preferences of Hispanic consumers: Cultural relevance of product attributes as a moderator. J Bus Res. 2009 Aug 1;62(8):826-33.

13. Leonard KM, Cosans C, Pakdil F. Cooperation across cultures: An examination of the concept in 16 countries. Int J Intercult Relations. 2012 Mar 1;36(2):238-47.

14. Marcus A, Aykin N, Chavan AL, Day DL, Gould EW, Honold P, et al. Cross-cultural userinterface design. In: Extended Abstracts on Human Factors in Computing Systems - CHI '00. New York, USA: ACM Press; 2000. p. 299.

15. Jiang J, Kandachar P, Freundental A. Exploring the Influence of design culture on ICT healthcare product \& service design for rural China. In: ERSCP-EMSU Conference. Delft, The Netherlands; 2010.

16. Razzaghi M, Ramirez M. The influence of the designers' own culture on the design aspects of products [Framework]. In: EAD06 European Academy of Design International Conference. Bremen, Germany; 2005.

17. Coelho DA, Silva ASC, Simão CSM. Culturally Inspired Design: Product Personalities to Capture Cultural Aspects. In: Industrial Design - New Frontiers. InTech; 2011.

18. Peranginangin E, Chen K, Shieh M-D. Cross-cultural consumer's Kansei research :the studi of product need on male and female. J Arts Sci Commer. 2011;2(1):11-6.

19. Reinecke K, Bernstein A. Improving performance, perceived usability, and aesthetics with culturally adaptive user interfaces. ACM Trans Comput Interact. 2011 Jun 1;18(2):1-29.

20. Cyr D, Head M, Ivanov A. Design aesthetics leading to m-loyalty in mobile commerce. Inf Manag. 2006 Dec 1;43(8):950-63.

21. Cawthon N, Moere A Vande. The Effect of Aesthetic on the Usability of Data Visualization. In: 2007 11th International Conference Information Visualization (IV '07). Zurich, Switzerland: IEEE; 2007. p. 637-48.

22. Moshagen M, Thielsch MT. Facets of visual aesthetics. Int J Hum Comput Stud. 2010 Oct 1;68(10):689-709.

23. Parizotto R, Hammond N. Does aesthetics the user's perception of VLE's,. In: The 12th International Conference on Artificial Intelligence in Education. Amsterdam; 2005.

24. Fawcett P, Fisher KE, Bishop AP, Magassa L. Using design thinking to empower ethnic minority immigrant youth in their roles as technology and information mediaries. In: Extended Abstracts on Human Factors in Computing Systems on - CHI EA '13. New York, USA: ACM Press; 2013. p. 361.

25. Fereidouni HG. Cultural attitude towards print media advertising of controversial products among female consumers in Penang Research report in partial fulfillment of the requirements for the degree of MBA. Universiti Sains Malaysia; 2008.

26. Satriani S. Komposisi warna etnik dayak sebagai pembentuk image budaya pada olahan desain interior. Institut Teknologi Sepuluh Nopember; 2012.

27. Merritt A. Replicating Hofstede: A study of pilots in eighteen countries. In: Proceedings of the Ninth International Symposium on Aviation Psychology. 1997.

28. Itim International. The Hofstede Centre: Cultural Survey Report. Hofstede Insight. 2013.

29. Minkov M, Hofstede G. Hofstede’s Fifth Dimension. J Cross Cult Psychol. 2012 Jan 15;43(1):3-14.

30. Nikolic M, Torre M La, Lalić G. National Culture Values: reflections on formation process of future leaders in international economic cooperation. J Educ Cult Soc. 2013;(2):217-26.

31. Anjum M, Zia SM, Raza H. Cultural Dimensions of Pakistan: A Comparison of Sindh, Punjab, 
Balochistan and Khyber Pakhtunkhwa Provinces. Int J Manag Sci. 2014;4(6):261-76.

32. Hofstede G. Culture's consequences : international differences in work-related values. Beverly Hills, California: Sage Publications; 1984. 327 p.

33. Zhao F. Impact of national culture on e-government development: a global study. Internet Res. 2011 Jan 28;21(3):362-80.

34. Löfgren M, Witell L, Gustafsson A. Theory of attractive quality and life cycles of quality attributes. TQM J. 2011 Mar 16;23(2):235-46.

35. Dwyer L, Mellor R. New product process activities and project outcomes. R\&D Manag. 1991 Jan 1;21(1):31-42.

36. Wenzlaff K. Youth, culture, negotiation and politics. Asia Eur J. 2008 Jan 11;5(4):573-94.

37. Lim P. Notes on Europe and Asia: Towards a new European strategy. 2002.

38. Lawson S. Europe and the Asia-Pacific: Culture, Identity and Representations of Region. 2002.

39. Crothers L, Lockhart C, editors. Culture and Politics. New York: Palgrave Macmillan US; 2000.

40. Trompenaars A. Riding the waves of culture : understanding diversity in global business. Burr Ridge, Illinois: Irwin Professional Pub; 1994. 215 p.

\section{Acknowledgments}

The article was prepared within the framework of Success Product Development, part of Dissertation in Mechanical \& Industrial Engineering, Gadjah Mada University, Indonesia. 